\title{
The Romanian- Russian Bilateral Register as a Symbolic Projection under the Folds of Immediate History
}

\author{
Trandafir (lancu) Miruna Mădălina
}

Postdoctoral Researcher, PhD, Faculty of Sciences and Letters, Petru-Maior University of Târgu-Mureș, Romania

Doi:10.5901/ajis.2015.v4n3s1p229

\section{Abstract}

\begin{abstract}
The present research approach places in its analysis nodal center the achievement of an interdisciplinary research in a unique area of crucial interest for the social sciences field, namely that of public image - public image which actually refers to an attribute of psychic life based on the capacity of human psychic to build mental representation, and is subsumed to the study of images-. In other words, in the research undertaken, the central scientific interest will focus on the issue regarding the image which presents itself as an impression created in the public's mind about a person, institution, product or a particular phenomenon, in this case referring implicitly to the public image assigned to the Romanian-Russian bilateral register in the immediate period. Starting therefore from the realities ascertained in the previous researches undertaken with regards to the Romanian-Russian immediate relations, in the present research attempt, we aim to highlight the manner in which the Romanian-Russian algorithm has been configured as a symbolic projection and a psychological reality under the sign of immediate history. Succinctly, this research attempt desires to be first of all and in a patented manner, a coherent and rennet approach to complement all that the immediate constellation of Romanian-Russian bilateral relations means, implies and presupposes as a collective representations fresco. Integrally, this research approach aims to be an investigative format that thus addresses a completely distinct facet of the bilateral spectrum issue, in fact pays considerable attention to the dynamics of the bilateral register.
\end{abstract}

Keywords: public image, symbolic projection, bilateral register, Romania, Russia, immediate history.

\section{Introduction}

For the most specialists advised in the field, the analytical horizon related to the current Romanian-Russian binomial is not an easy one, the more so because it implies a laborous demarche in relation to a report which reflects in an conclusive manner, an atypical, discontinuos and even syncopated portraiture. Fragmented rather than linear, the Romanian-Russian relationship has unraveled and continues to presently unravel in a sinuous and imprecise manner with little concrete signals of mutual cooperation, obviously contrasting with the perpetual periods of recoil and suspension. It particularly borders on an ambivalent mistrust, subordinate to a convulsed history, encumbered by light and shadow, responsible for shaping these relations. Precisely because of these considerations, ,the usage of classical instruments afferent to the analysis of international relations is insufficient for understanding the type of interactions which exist between Romania and Russia. The usage of the methods pertaining to the collective imaginary psychology is necessary in order to attain the goal proposed" (Abraham, 2006). In other words, in order to understand exactly the complexity inherent to the Romanian-Russian immediate universe, it is more than necessary to understand the manner in which this bilateral register appears and is perceived as a psychological reality and as a symbolic projection during the entire period mentioned. On these lines, this is exactly what the preseant research approach intends to highlight and to demonstate in the following section.

\section{The Bilateral Register as a „Universe Of Contrasts” under the Folds of Immediate History}

Undoubtedly and undeniably, the Romanian Revolution of December 1989 has represented a nodal trademark for the establishment of a new type of relations between Romania and URSS. De facto, the changes in December 1989 have imposed, at the level of the new Romanian political elite, and at the level of the temporary political formation entitled, National Salvation Front" (lliescu, 2011) respectively, the necessity for crystallizing an eminently distinct frame of approach towards the rapports with the Eastern neighbor, more exactly, a frame within which a philosophy of normal rapports with the Soviet Union is primordial. Actually, within this strategy of inherent corrections, tributary to the bilateral spectrum, strategy that pleaded for the restoration and reestablishment of a „modus vivendi” (lliescu, 2011) at a bilateral 
level, but also for blurring until extinction the remains of the old regime, has been inscribed both the policy of rapid start, characterized by an exceptional dynamics of the contacts established between the two countries in 1990, and the attempt to reconfigure the judicial physiognomy of the bilateral rapports, attempt that was ultimately doomed to fail.

However, this preliminary dialectics on the basis of which the governing elite has acted with the view to reconsider the type of relations existing at that present time between the two countries, couldn't ignore the dimension of certain episodes that proved to be true moments of difficulty for the bilateral rapports zodiac, but also the most difficult to surpass exams at a bilateral level. Thus, events such ,,as the dissolution of the Warsaw Pact” (Filip, 2006) and ,the retrograde putsch in Moscow" (Graciov, 1995), beyond the fact that they have directly affected the Romanian state, they couldn't ignore the bilateral rapports spectrum, placing an implacable print on the following evolution of the bilateral itinerary. Actually, for the governmental formation whose foremost representative was President Ion lliescu, the most difficult test was to elaborate a strategy, susceptible to ignoring and abandoning the crucial implications that the dimension of such episodes could have induced at the level of bilateral relations mechanism. Naturally and predictably, in the absence of an intuitive political spirit, and under the skirts of an inconsistent approach and vision, for the governmental structure whose undeniable leader was President Ion lliescu, such a test was insurmountable from the beginning. This is precisely why it is not surprising that towards the end of 1991, but especially under the political reign of the fesenist structure, there have been no substantial changes nor notable advances in the bilateral relations dimension, the political formation that took over leadership of Romania after December 1989 thus succeeding the performance to leave the relationship with URSS uncultivated, but also to contribute to the situation in which the bilateral relations have registered a considerable and visible impasse.

Besides, the context created by the de facto disappearance of the Soviet Union and by the takeover of main prerogatives by the Russian Federation, had not induced spectacular mutations at the bilateral register level either. Although it should have represented the nodal event in which the Romanian-Russian bilateral rapports dimension was about to be inscribed on the alignment of inherent normality and political evolution, the episode occasioned by the official death of URSS had proved to be the exact opposite, the collapse of the Soviet giant leaving thus behind both a bilateral cleavage and an almost void space in what concerns the relations with its main successor, Russia. In addition, not even the event occasioned by the affiliation of the Romanian state to the Euroatlantic structures hadn't generated background mutations at the bilateral thopos level, and hadn't fundamentally changed the decorum of relations with the Russian Federation. Quite the contrary, in the context where the objective of re-coupling the Romanian state to the Euroatlantic constellation prevailed, the governing elite had no longer manifested a special appetite for establishing a substantive dialogue, compensating for the Eastern proximity. Moreover, the epic of reinserting the Romanian State on the institutionalized Europe coordinates has contributed to foreshadowing the two interludes (the cleavage interlude and the bilateral cooling), interludes that have reinstated in the most eloquent manner the true frame of mind that has characterized the bilateral register at that time. Thus, if on the occasion of the bilateral cleavage interlude ,"- on which the government of the Romanian Social Democracy Party (President Ion lliescu's party) had placed an undeniable print - the zodiac of Romanian-Russian bilateral rapports was characterized by a definitive rupture, strengthened by the differences of opinion within both parties with regards to problematic aspects" (Popa, 2001), with the occasion of the bilateral cooling interlude (1996-2000) ,, - draped under the skirts of President's Emil Constantinescu Romanian Democrat Convention policy -, the Romanian-Russian bilateral rapports itinerary was strongly encumbered by the deliberate will from both sides to maintain the constellation of the bilateral relations under such a completely blocked and ill climate" ( Severin,2012).

Consequently and in these conditions, the ensemble image taken is the one that highlights that under the coordinates of the 3 leaders (FSN, PDSR, CDR), the configuration of the Romanian-Russian bilateral rapports has held a syncope texture, and the evolution of the bilateral tandem has oscillated between a short episode of advance on a bilateral level (1990) and the perpetual moments of inflexion and recoil characteristic to the bilateral spectrum, the portraiture of immediate relations thus being strongly embossed both by the communist halo and by the burden of a burdensome historical litigation.

Therefore and in this optics, if within the previous scene it has been revealed how the main political actors that stood at Romania's leadership between 1990-2000 have chosen to shape and outline the landscape of the immediate Romanian-Russian relations, within the next one, the main objective was to see how the film of Romanian-Russian bilateral rapports has been calibrated, under the montage of PSD and DA Alliance government, that have held the political reigns between 2000-2007. In this sense and from an explicit desire to highlight the coloring specific to the bilateral dimension for each individual government, the main scientific interest was to resort to a clear delimitation between the two periods, referential for the configuration of the immediate binomial, the period 2001-2004 and 20052007, respectively. 
Naturally and as expected, it can be observed, on the basis of an integrated optics, that the above mentioned periods has clearly portrayed a picture that sums the perennial moments of flux and reflux, characteristic to the bilateral zodiac. This is practically why, if with the occasion of the first period, but also under the leadership of a social-democratic political elite - elite that has otherwise assumed the audacious task to fundamentally re-think the nature of some eminently blocked and vitiated rapports, and to also bring them to an incentive level - there have been recorded a series of notable advancements on a bilateral level, that have culminated with the episode of signing ,,the Romanian-Russian basic political Treaty in July 2003" (Matache, 2003), on the occasion of the second stage and implicitly under the coordinates of a liberal-democratic political elite, the course of Romanian-Russian bilateral relations that had initially started under the best of auspices, has shortly met the valences of enhanced global cooling, extremely difficult to reacclimatize. The reference is thus to a first period on the occasion of which the social-democratic political elite, that had positioned itself as an active factor in the relations with the Russian Federation, has pointed its strategic and tactical instruments towards restoring the dialogue with Russia in the foreground, as well as towards re-engaging the bilateral mechanism in all possible ways. A more than eloquent proof to this has been certified by the obvious ascending and progressive trend registered by the bilateral course ever since 2001 on the basis of a policy, grinded on deepening the high level dialogue, and has met its height through signing of the Treaty for amity and cooperation between Romania and the Russian Federation on 4 July 2003, respectively through signing the judicial instrument, susceptible to revitalizing the bilateral frame, but also to eliminating historic and psychological barriers that had obstructed until that moment, a natural and normal bilateral evolution.

Thus, if the entire period of 2001-2004 stood under the mark of the social-democratic political elite's will to confer substance and essence to the Romanian-Russian bilateral relations configuration, the probing testimony of this will being certified by the progressive current of the bilateral course ever since 2001, persistently maintained until 2004, the period 2005-2007 stood under a zodiac of capital changes in the rapports with the Russian Federation. Thus, although for the new liberal-democratic political elite sponsored by President Traian Băsescu the relations with the Russian Federation were of great interest in terms of a range of factors, as soon as possible, however, this vision involved a radical change of optics. This is practically why, if in 2005, under the dome of President Traian Băsescu's lines of action, the relations with the Russian Federation were commencing in a thoroughly enthusiastic and promising logic, announcing a natural and normal itinerary at a bilateral level, at the end of the year, on the basis of an eminently intransigent account - seasoned with unfriendly and bellicose declarations towards Russia -, President Traian Băsescu was succeeding, slowly but surely, the performance to freeze and to cripple any bridge of communication with the Russian Federation. Actually, such a frondist policy, seasoned with elements of strident language towards Russia, had represented both an immutable constant, and the main characteristic that embossed the evolution of the bilateral tandem over the following years as well. In addition, the situation was not going to record notable changes not even in 2007, when it was perfectly clear that at the bilateral relations frame level, a clearly revolutionary tone was to prevail, and it was evident that the future perspectives of the bilateral repertoire were not anticipating pleasant elements, thus continuing to predict a bilateral route strongly impregnated by the feature, and the game that President Traian Băsescu chose to attribute to the bilateral dimension.

In conclusion, one can appreciate that the image subtracted from this landscape of eclectic formulas on the basis of which the main political decision makers have chosen to approach the bilateral context, is the one that highlights the fact that besides the passenger episode whose protagonists were the Social-Democrat Party leaders, leaders that have focused their entire strategic and tactical interest towards conferring a new course to bilateral relations, with the occasion of all the other governments, the paradigm of approach, tributary to the bilateral ethos, was separated through a lack of substance and consistency, thus evidently lacking a clear and coherent strategy of managing and implicitly developing the relations with Russia. Practically, with the exception of the PSD government interlude, at the level of all other governing formations there has not been seen a direction of action susceptible of articulating an active, autonomous policy, adapted to the nature of complexity, exceptional and specific character of the bilateral thopos. In other words, there has not been a doctrine of Romanian external policy specifically stalled on the reality of bilateral space.

Therefore, if it is perfectly valid the aspect according to which a clear, linear, and substantive direction of action could not be identified at a majority level of the governing elite, thus implicitly there has not been a strategy with a specific coloring of the bilateral zodiac, but also a strategy that truly induces a major and in-depth change on bilateral relations, it is as true that under such conditions, neither the configuration of immediate Romanian-Russian relations has held a different chromatics. De facto, with the occasion of this immediate historiographical register, the balance picture, afferent to the bilateral zodiac, had highlighted a universe of contrasts, taped with short episodes of bilateral expansion, but most of all with perennial moments of inflexion and recoil characteristic to the bilateral thopos. In other words, under the constellation of immediate history, the Romanian-Russian bilateral dimension has revealed an atypical, discontinuous, 
and mostly syncope configuration, evolving mostly on the basis of a sinuous and rough grid, rather than on the basis of linear, precise, and constant evolution parameters. At the same time, it is not less significant that in this section of immediate history, the Romanian-Russian bilateral rapports register could not ignore the historical ambiance, cosubstantial to the bilateral frame, rearranging and reconfiguring itself in relation to the communist period and implicitly to the burdensome bilateral legacy. In addition, beyond the perennial, thorny aspects, co-substantial to the bilateral register, with the occasion of the immediate interlude, the Romanian-Russian bilateral agenda had added an extra set of subjects and hot topics that have caused considerable issues for the bilateral dialogue.

Thus, if it is true that the portraiture of immediate Romanian-Russian rapports was highlighted by a syncope dimension, and has revealed a chromatics of bilateral contrasts, re-configuring itself in relation to the weight of an obsessive past, it is as true that the dimension of Romanian-Russian political relations dimension has registered, with the occasion of the immediate interlude, an extremely low level of development, below the level of expectations and existing potential. In few words, in the immediate history section, the Romanian-Russian political relations physiognomy was eminently "rigid and blocked, with certain moments that have otherwise been true exceptions, thus implicitly under the skirts of immediate interlude, neither Romania nor Russia have had an existential stake in building a fundamentally normal political relation" ( Dungaciu, Tănăsescu, 2013) .

\section{Conclusions}

Subsequently and in this optics, respectively in the context where the immediate Romanian-Russian episode can be diagnosed as an universe of contrasts, inducing a recurrent deja-vu sensation with regards to the bilateral choreography, specific to the previous interlude, but also taking into account the conjuncture in which the political dimension of bilateral relations can be considered void of pragmatism, of debate, but mostly of content, an heuristic approach of the bilateral dimension is imposed, an approach susceptible to eliminating the deficit at a bilateral level. From a palette of pivotal reasoning, of an economic, political, cultural, scientific, security order, the Romanian state, through the voice of its governing elite can not afford the luxury to manage the relations with Moscow in a conjuncture and fundamentally deprived of content, manner. Ultimately, the Bucharest decision makers must take into account that Romania can not build trenches in its Eastern proximity, quite the contrary, the Romanian state, through the voice of its legit political representatives, needs to approach responsibly and with maximum interest the dimension of Romanian-Russian bilateral relations, to build substantive realities at a bilateral level, to find a common action language through which it can accelerate the collaboration in all areas of mutual interest, in short, to restore the bilateral rapports constellation to its true parameters of normality and political evolution.

\section{References}

Abraham, F. (2006). The Transformation of Romania 1989-2006, The Role of External Factors (p.184). Bucharest: National Institute for the Study of Totalitarianism

Dungaciu, D., Tănăsescu, G. (2007) Romania and Russia after 20 years: Perceptions, Realities, Perspectives (pp.6-7), Bucharest: Institute of Political Sciences and International Relations

Filip, C. (2006). The Warsaw Pact. A political and military organisation under Moscow (pp. 179-180).Târgoviște: The Fortress

Graciov, A. (1995). Gorbachev's shipwreck: the true history of the Soviet Union's disintegration (pp.264-265). Bucharest: Nemira

Iliescu, I. (2011), Fragments of life and history lived (p.77), Bucharest: Litera Publishing House

Interview with Ion lliescu, Former President of Romania between 1990-1996, taken at 11 May 2011

Interview with Adrian Severin, Former Minister of Foreign Affairs between 1996-1997, taken at 16 March 2012

Matache, Cristian (2003). It's time to get down to facts, [Available] Online: http://www.cronicaromana.ro/e-timpul-sa-trecem-lafapte.html?sirc=relatiile,\%20romano-ruse, (July 5, 2003)

Popa, C. (2001). Under the sign of counter historical time. An attempt to assess the relations between Romania and URSS/ Russia (p.48). The Political Sphere

The funding for the publication of the present paper has been done by the Sectorial Operational Programme for the Development of Human Resources through the project "Integrated system of improving the quality of doctoral and postdoctoral research in Romania and of promoting the role of science in society": POSDRU/159/1.5/S/133652. 